Cuad. invest. hist. Brocar n. 16 (1990). Págs. 61-70.

\title{
AGONCILLO Y SU FORTALEZA
}

\author{
Inocencio Cadiñanos Bardeci
}

\begin{abstract}
RESUMEN.- Agoncillo es un lugar de origen romano situado en un punto estratégico pues dominó un vado sobre el Ebro. Con la fijación medieval de la cercana frontera navarra cobra aún mayor valor defensivo. La fortaleza suena por primera vez en el siglo XII. En plena Edad Media pasa a poder de los señores de los Cameros y despues, sucesivamente, a los Rojas, Medranos, Garcia de Porras y Frías Salazar. Parece que la más antigua fortaleza se corresponde con la gran torre del sur. La pequeña, cercana a la iglesia, es del siglo XIV, siendo construido el resto por Pedro Gómez de Porras. El resultado fue una amalgama de edificaciones como también lo confirma su irregular plano. En todo predomina una excelente sillería.

SUMMARY.- Agoncillo is a roman origin place located in a strategical point because it overlooked a ford abore Ebro. It has a bigger defensive value with the medieval settlement of the nearby navarra borderline. For first time, the fortress appears in the XIIth century. In the Middle Age, Cameros are the owners of it and afterwards to Tojas, Medranos, Garcla de Porras and Frtas Salazar. It believes the aldest fortress is related with the big southern tower. The small one, next to the church, dates from XIVth, and the rest ofit was built by Pedro Gómez de Porras. The consequence was a mixture of buildings which it's ratified with its irregular forms. There 're excellent stones all over the buildings.
\end{abstract}

Palabras clave: Valle del Ebro, Agoncillo, Fortificación, Edad Media/Moderna.

\section{CONDICIONANTES HISTÓRICOS Y GEOGRÁFICOS}

Ha sido un tópico el atribuir los puentes a los romanos y las cuevas, peñas bravas y castillos a los moros. Y esto en casi toda España.

Mientras que los musulmanes estuvieron varios siglos ocupando la Rioja hasta las Conchas de Haro, rio arriba del Ebro por el contrario, tan sólo recorrieron esporádicamente las tierras de Miranda, Valdegovía o las Merindades. Se trata de la "Al-quilá", o los castillos, como decían, y que daría lugar al nombre actual de Castilla. Efectivamente, la más vieja Castilla se caracterizó por numerosas defensas con elementos específicos que faltan casi por completo en las muy posteriores de la Baja Edad Media, como es el caso de Agoncillo. Aquéllas eran enriscadas, poco espaciosas, incómodas, 
construidas a base de materiales resistentes hallados al pie del edificio, dotadas de ingeniosos medios defensivos, ayunas de todo lujo pues no tenian más sentido de la permanencia que la circunstancia guerrera del momento y el control de pasos importantes. Así eran, por ejemplo, Pancorbo y Lantarón y más abajo, por tierras riojanas, Ibrillos y Grañón, todas muy parecidas entre sí.

Las formas de castramentación sufren una notable evolución desde que la Rioja queda libre de musulmanes, aunque mantengan algún importante detalle defensivo. El castillo de las luchas navarro-castellanas de los siglos XI y XII es un término medio entre las antiguas fortalezas y las bajomedievales caracterizándose por su simplicidad puesto que su firalidad se reduce a vigilar pasos estratégicos importantes ya sea del propio Ebro o de los estrechos abiertos por él mișmo o sus afluentes. Buenos ejemplos se encuentran entre la Bureba y las Merindades (Tedeja, Petralata...) pero también es el caso de la más antigua fortaleza de Agoncillo, como veremos.

Con el asesinato de Pedro I desaparecen las grandes familias de los Laras, Castros y Haros. Una nueva nobleza advenediza surge en nuestra tierra y se reparte sus bienes. El nuevo patrimonio estará integrado por donadíos reales más a menos legales pues en muchos casos proceden de los momentos de debilidad de la corona (Enrique II) o arrancados a monarcas abúlicos (Juan II y Enrique IV). Los usufructuarios (y buen ejemplo serán los de Agoncillo) tienen que defender un patrimonio disputado. Posteriores compras, donaciones, agregaciones con matrimonios interesados y expolios a los campesinos, e incluso a la Iglesia, obligan a permanecer vigilantes.

Todo ello exige una eficaz defensa del patrimonio y, si es posible, con escasos medios defensivos puesto que mantener permanentemente un pequeño destacamento resultaba excesivamente gravoso para una fortuna limitada como es el caso que estudiamos. Un alcaide, unos criados y las consiguientes armas eran suficientes para, desde la fortaleza, dominar a los colonos, exigir sus contribuciones y asegurar las rentas almacenadas. El hecho de que ricas granjas y algunos monasterios tomen contemporáneamente la misma precaución, demuestra su eficacia disuasiva. Hay que huir, pues, de explicaciones fantásticas, leyendas y batallitas reduciendo nuestra fortaleza a una realidad tan práctica que hasta cabria calificarla de prosaica. Agoncillo, como tantos otros casos riojanos, es una casa fuerte con acusados caracteres de fortaleza, refugio en época de revueltas, amenaza constante de colonos morosos y centro de una gran explotación agraria cuyos dueños son señores del lugar con especiales derechos, incluso, en su templo parroquial.

\section{LA FORTALEZA}

a) El emplazamiento: Los varios restos arqueológicos hallados en los contornos de Agoncillo parecen confirmar un origen romano del pueblo. Hasta podria atribuírsele una mayor antigüedad pues su nombre parece proceder de una divinidad céltica como lo recuerda el término Valdegón. Cerca del lugar pasaba una calzada romana y aún se conservan restos de un puente de aquella época imperial.

Se halla nuestro pueblo en un punto estratégico claro: a orillas del Ebro, cerca de 
su confluencia con el río Leza y junto a la raya de la antigua frontera del reino navarro. A todo ello habría que añadir su cercanía a un importante vado en el Ebro (el conocido Gronio) o sea la capital provincial, lo que claramente acentuaba su valor estratégico a la hora de controlar Logroño.

b) Los dueños: Medranos, Porras y Frías Salazar: En la segunda mitad del siglo XI el rey navarro vendia a Sancho Fortuniones los lugares de Villanueva y Agoncillo. Este lo traspasaría al monasterio de San Juan de la Peña. De haber tenido un notable valor defensivo es muy probable que no hubiera sido enajenado a un monasterio.

Aprovechándose de la minoria de Alfonso VIII, el rey navarro se hace con la zona que estudiamos. En 1168 este último monarca ponía en Antelana y Agoncillo a García Bermúdez como tenente. Es la primera mención de una fortaleza y hasta es probable que fuera levantada por entonces con el fin de controlar la cercana frontera. Y con la fijación de ésta, lógicamente, aumenta el valor estratégico del lugar.

En siglos posteriores consta que Agoncillo forma parte del rico patrimonio de los señores de los Cameros, los Alfonso de Haro. En su castillo tendría lugar la trágica degollación de su dueño. Como narra la crónica real, el enérgico Alfonso XI se vería forzado a dejar el cerco de Gibraltar para acudir a sitiar en Lerma al poderoso Juan de Lara. A marchas forzadas apareció en Agoncillo sorprendiendo a Juan Alfonso de Haro en su fortaleza y allí mismo le declaró traidor degollándole a continuación. El monarca entregaria a Sancho Sánchez de Rojas "el logar de Agoncillo con sus términos, rentas y justicia...” (Año 1336), con todo lo cual formaría un mayorazgo.

Valiéndose de las dificultades castellanas durante las luchas fraticidas de Pedro I y Enrique II, el rey navarro se hizo temporalmente con Logroño y Agoncillo. Para pagar las aportaciones hechas a la campaña por los vecinos de Viana, el monarca vendía "Agoncillo... con su castillo... que nos avemos de nuevo ganado y conquistado" por precio de 3.100 florines. El documento de venta tiene un original detalle digno de señalarse: el rey da nuestra fortaleza "por cassa plana... del qual castillo no seades tenidos facernos omenaje..." De lo que se deduce que el concepto de casa fuerte dependía más de una consideración legal subjetiva que del tipo de arquitectura especial que estamos estudiando.

Pero pronto volvió Agoncillo a Castilla y a sus auténticos dueños los Medrano. El comprador habia sido Diego López de Medrano a fines del siglo XIV. Concretamente, entre otros bienes, compraba en 1392 a Rodrigo Alfonso "el lugar de Agoncillo que es cerca de Logroño con la casa fuerte y piezas y viñas... e con todo el derecho y señorío... en troque de la casa y torre de Islallana... con quarenta mill mrs. porque valía más el dicho lugar de Agoncillo". A comienzos del siglo XV formaba mayorazgo para su hijo. A través de una hija pasaría a los Gómez de Porras.

Estaban los Porras (o Porres) ricamente heredados en tierras de la cuenca alta del Ebro perteneciéndoles las torres de Cidad de Valdeporres, Virtus, Puentedey y Extramiana. El paso de Agoncillo a los Porras fue irregular y por la fuerza como nos lo recuerda Lope García de Salazar en sus Bienandanzas: “este Diego López (de Salcedo) fue trauajado e gastado por cobrar la casa de Agonçillo que le pertenecía por su madre... porque la entraron por fuerça". De nuevo el pueblo y su fortaleza volvían 


\section{INOCENCIO CADIÑANOS BARDECI}

a ser centro de un rico mayorazgo. Sus señores se enterrarían en la capilla mayor del convento logroñés de San Francisco.

A fines del siglo XV Lope de Porras daba en arriendo a los vecinos del pueblo su término redondo por un censo anual de 1.000 fanegas de pan, 8.000 maravedís, 50 gallinas, más diversas prestaciones personales para su reserva. El alcaide que pusiera en la casa fuerte podría pastorear libremente 100 cabezas de ganado lanar en dicho término.

Agoncillo continuó en los Porras hasta fines del siglo XVI en que pasa a los condes de Siruela. La última poseedora lo fue una hija del conde de este título, monja clarisa en Medina de Pomar. Con su muerte pasó al apellido Frías Salazar hasta principios del siglo XIX en que es abolida la jurisdicción señorial y, también, los mayorazgos. Con anterioridad los empobrecidos colonos habian intentado revertir a la corona sin conseguirlo. Pioneros en el intento, serían ejemplo para otros que tendrían mejor suerte.

Aunque caducados sus derechos señoriales, los Frías Salazar alcanzarían de Alfonso XII, en 1875, el título honorífico de marqueses de Agoncillo. No habitaron casi nunca su incómoda fortaleza sino que a través del tiempo viven en alguno de los populosos lugares de los contornos o bien en Logroño cuya casa solar blasonada aún podemos contemplar en la Rua Vieja.

c) Análisis del edificio: plano, elementos y transformaciones: Habria que situar entre Agoncillo y Arrúbal el antiguo castillo denominado Castillo Rubio. También parece que en el cercano término de Costarán hubo otro punto fortificado enlazado con el del pueblo por un túnel. Los vecinos lo recuerdan nostálgicos: "Costarán, Costarán quién te ha visto y quien te ve...".

En 1188 consta como tenente "in Agoseilo et in Antelana (Entrena) García Bermudez". Los autores de los cartularios riojanos han reducido equivocadamente el primero al lugar de Ausejo cuando es seguro que se trata de nuestro Agoncillo. Veinte años después, los hijos del mencionado tenente concertaban con Alfonso VIII un pacto respecto al castillo que Alfonso VII había entregado a su abuelo, y que ahora estaba bajo el "amparo" castellano. Prometieron no hacer daño al rey desde él y, en reciprocidad, éste no le tomaría por la fuerza y seguiría amparándole.

En tiempos del Alfonso XI no sólo servía de refugio al señor de los Cameros, como ya se dijo, sino que el lugar cobra cierta importancia fronteriza puesto que era "puerto seco" respecto a las mercancías procedentes de Navarra lo que potenciaba aún más el valor de su fortaleza.

La más primitiva construcción habría que identificarla con la torre del sur. Por su plano puede cosntatarse que es bastante mayor que las otras y a simple vista se comprueba que pertenece a una época distinta al resto de la fortaleza. Los sillares son irregulares, pequeños y de menos perfección en la trabazón de sus materiales. No conserva matacanes y es posible que no los haya tenido nunca. Sus almenas estarían sobre la vertical de los muros o muy poco salientes a juzgar por un reborde del extremo superior del que todavía queda algún resto. Si exceptuamos la puerta de acceso al camino de ronda, que seguramente es posterior, sus vanos se reducen a unas escasas saeteras. Interiormente posee cuatro plantas, tres de ellas sostenidas por bóvedas de 
cañón correspondientes, muy probablemente, al período románico. Recuerda mucho a las musulmanas por sus proporciones, formas y volumen. Los citados elementos constructivos, y algunas otras circunstancias históricas, podrían inducir a pensar que la torre se corresponde con la levantada a fines del siglo XI como garantía de la nueva frontera castellano-navarra custodiada por el "enemigo malo" del Cid y frente a la no muy alejada zona musulmana.

De ser así Rodrigo Alfonso construiría a mediados del siglo XIV la torre pequeña cercana a la parroquia, y el lienzo que enlaza ambas torres en el que se abre la entrada. Todo lo dicho es muy probable pues la cruz grabada sobre la puerta corresponde al primitivo escudo de los Medrano y no es la de Calatrava como tantas veces se ha repetido. Aunque más pequeña, la citada torre es de proporciones más equilibradas que la anterior y de elementos constructivos más perfectos. Conserva algunos restos de matacanes por sus cuatro lados.

La fortaleza de "Aguas Mansas" (algunos vecinos dicen "Aguas Muertas") tal como se conserva hoy día, se la debemos a Pedro Gómez de Porras, Así hay que deducirlo necesariamente de su testamento: "otrosí por quanto nosotros hemos edificado juntamente (se refiere a su mujer) esta casa de Agoncillo sobre seiscientos mill maravedís de gastos en la labor della mandamos (que se descuente...)". La cantidad consignada es altisima para la época. Pedro debió de construir la mayoría de lo que actualmente podemos contemplar, incluida en líneas generales, también su distribución interior.

Por encontrarse Agoncillo en una llanura no se alzó el castillo, como ocurre normalmente, en una eminencia. El aprovechamiento de construcciones anteriores y su finalidad palaciega hizo que se levantara en el centro del pueblo y completamente en 1lano. Dentro de la provincia riojana su plano recuerda a la de Leiva y cada una de las torres levantadas por Pedro, a las de Anguciana y Baños de Rioja.

El edificio está hecho a base de excelente sillería muy regular y perfectamente ensamblada. Que fue una ampliación de elementos anteriores no cabe duda: la irregularidad del plano así como la unidad e igualdad de lo atribuido a Pedro son argumentos suficientes.y evidentes. La planta del edificio actual se aproxima a un cuadrado flanqueado por cuatro torres muy desiguales en las esquinas, con un saliente al norte más bajo que apenas llega a la categoría de torre. Toda la parte levantada en el siglo XV está recorrida de matacanes cuyos fuertes y perfectos canes se conservan bien, mientras que la coronación ya ha desaparecido en varios lugares. La cuádruple fila de modillones salientes ensanchan notablemente el espacio del adarve y los caminos de ronda. Los vanos son diferentes, la mayoría propios de la última etapa del gótico florido. Están protegidos por una pequeña visera. Los arquillos de algunas ventanas geminadas aparecen labrados en un sólo bloque de piedra. Pocas conservan aún las rejas. También las saeteras, muy asimétricas, son variadas como correspondientes a diferentes épocas. Las de la planta baja del noroeste son grandes y oblicuas. Las saeteras más modernas se encuentran bajo los vanos, adaptadas para el uso de armas de fuego.

Todas las torres comunican con el camino de ronda, que recorre los paramentos a través de portillo abiertos tardíamente puesto que sus arcos son de medio punto, tallados en un sólo bloque de piedra, excepto el paso de la grande que posee arco ojival. 
El sucesor del mencionado Pedro de Porras también hizo "varios reparos" que podrían referirse a la continuación y finalización de la obra realizada por su padre. Quizá a él se deba el patio construido a base de columnas toscanas que soportan lienzos de ladrillo tras los que se extienden las habitaciones. La distribución del interior está hecha basándose en los espacios dejados al unir los ángulos de las torres que al ser muy diferentes originan una desigual distribución de volúmenes.

En 1960 se hallaba nuestro castillo muy deteriorado, tanto que estaba inhabitable, apuntalada y reforzada la fachada con cadenas ya que manifestaba indicios de venirse abajo. El presupuesto necesario para repararle ascendía a la extraordinaria cantidad de 12.000 ducados.

Arriba se ha dicho cómo al morir en 1689 la condesa de Siruela se entabló pleito por Agoncillo. Antes de sentenciarse detentó el castillo durante seis años Lope de Frías Salazar quien llevó a cabo numerosas obras "de reparación", la mayoría completamente desacertadas ya que estropearon el edificio en gran medida. Por los interrogatorios sabemos que tenía foso y que entre éste y las paredes había unos terraplenes altos que Lope quitó para dar luz a las ventanas bajas. Es de suponer que entonces se cegasen dichos fosos de los que hoy día no se aprecia nada. La sala más importante se encontraba al noroeste llamada "Sala de Logroño", por mirar hacia esta ciudad. La torre más pequeña e inmediata se conocía con el nombre de "Las Palomas". Construyó Lope una cocina en la planta baja y para dar luz amplió los vanos destruyendo los anteriores, lo que se le criticó duramente y con razón. El destrozo podemos lamentarlo aún hoy día. Sobre la puerta de entrada estaba la "Sala de Invierno" y junto el lienzo más oriental la caballeriza en la planta baja y la conocida como "Sala del Obispo" arriba. Consta, además, que había una bodega y un espacioso silo para almacenar el trigo.

En la fortaleza solian vivir el administrador y algunos criados para quienes resultaba "la más decente vivienda de quantas en aquel contorno se conocen". Todavía a mediados del siglo pasado, según Gobantes, se encontraba en aceptable estado de conservación. Durante las guerras carlistas hizo de cuartel lo que unido a su posterior abandono acentuó su ruina.

Según los vecinos, el último dueño vendió el edificio a fines del siglo pasado por 1.000 duros a pagar en 20 años. Las huertas del contorno se vendieron aparte.

\section{LA FORTALEZA: PARALELISMOS Y PORVENIR}

La semejanza de nuestra fortaleza con otras contemporáneas, tanto locales como regionales y territoriales, es notoria. En la Rioja presentan torres cuadradas varios castillos. La de Baños de Rioja posee una planta semejante y fue levantada hacia el año 1500.

En Alava bastaría ojear el extraordinario trabajo de Micaela Portilla y fijarse en las dos de Fontecha, arriba de Miranda. Existen ejemplos parecidos en Navarra (Celigueta, Lesaca, Arazuri...). También en Soria y Guadalajara. En esta última, por ejemplo, la planta del castillo de Corduente es muy parecida a la de Agoncillo. Pero es lógico que 
el antes mencionado constructor de la mayor parte de la fortaleza, Pedro Gómez de Porras, se inspirara en las torres del alto Ebro. Alli poseía tanto él (Extramiana) como sus antecesores excelentes ejemplares como Virtus y Cidad de Valdeporres... Agoncillo presenta mucha semejanza con el palacio de Puentedey y, a través de él, con las casonas fortificadas de Cantabria. Posiblemente en este tipo de arquitectura hay que buscar en buena parte la inspiración de nuestra fortaleza.

En las Merindades predominan de forma aplastante las llamadas "Torres" de Medina de Pomar que también pudieron servir de modelo. Pertenecieron a los Velasco, muy heredados en la Rioja y a cuyo servicio estuvieron los Porras. Ambas (Medina y Agoncillo) presentan varias semejanzas: su finalidad intermedia entre palacio y fortaleza, se levantan en lugar llano y, en líneas generales, poseen un plano parecido. Por supuesto que existen otros muchos ejemplos burgaleses que presentan características semejantes a las de Agoncillo como Mazuelo de Muñó, torre central de Peñaranda de Duero, Olmos de la Picaza, Arenillas de Muñó etc. Sin embargo, respecto a todas las mencionadas la de Agoncillo presenta cierta originalidad puesto que es resultado de un conjunto de ampliaciones, aglutinantes de otras torres más antiguas, todo lo cual le proporciona una acusada irregularidad en planta.

Hoy día el aprecio general y la preocupación de Bellas Artes o entidades locales están posibilitando la recuperación de varios castillo. Por suerte, una de las asignaciones le ha tocado a Agoncillo. En ello habrán influido, seguramente, tanto la declaración de monumento histórico-artístico como el interés tomado por la dinámica Asociación Española de Amigos de los Castillos.

Las varías edificaciones que rodean casi por completo el edificio le afean, quitan perspectiva e incluso deterioran, Si pudiera llevarse a cabo una limpieza de elementos extraños todavía podría salvarse por completo pues sus parementos se mantienen sólidos a pesar de algunas grietas. El actual proceso de restauración no sólo deberá atender a su recuperación sino también a la consolidación de su interior, que todavía se halla en aceptable estado de conservación si le comparamos con otros monumentos locales y aún nacionales. Esperemos que asi sea y que se acierte en el intento. 


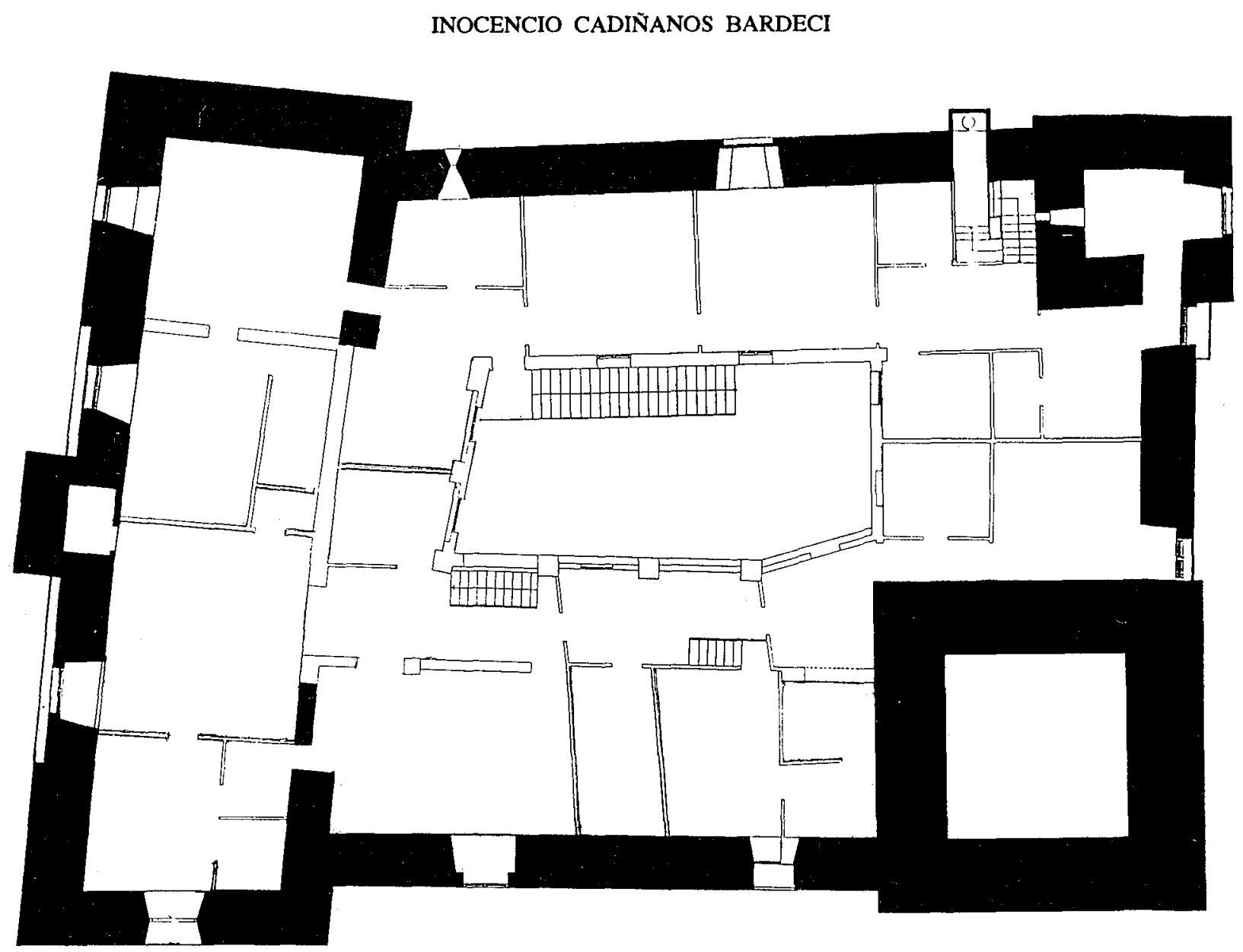

Fig. 1 Agoncillo. Croquis de su fortaleza.

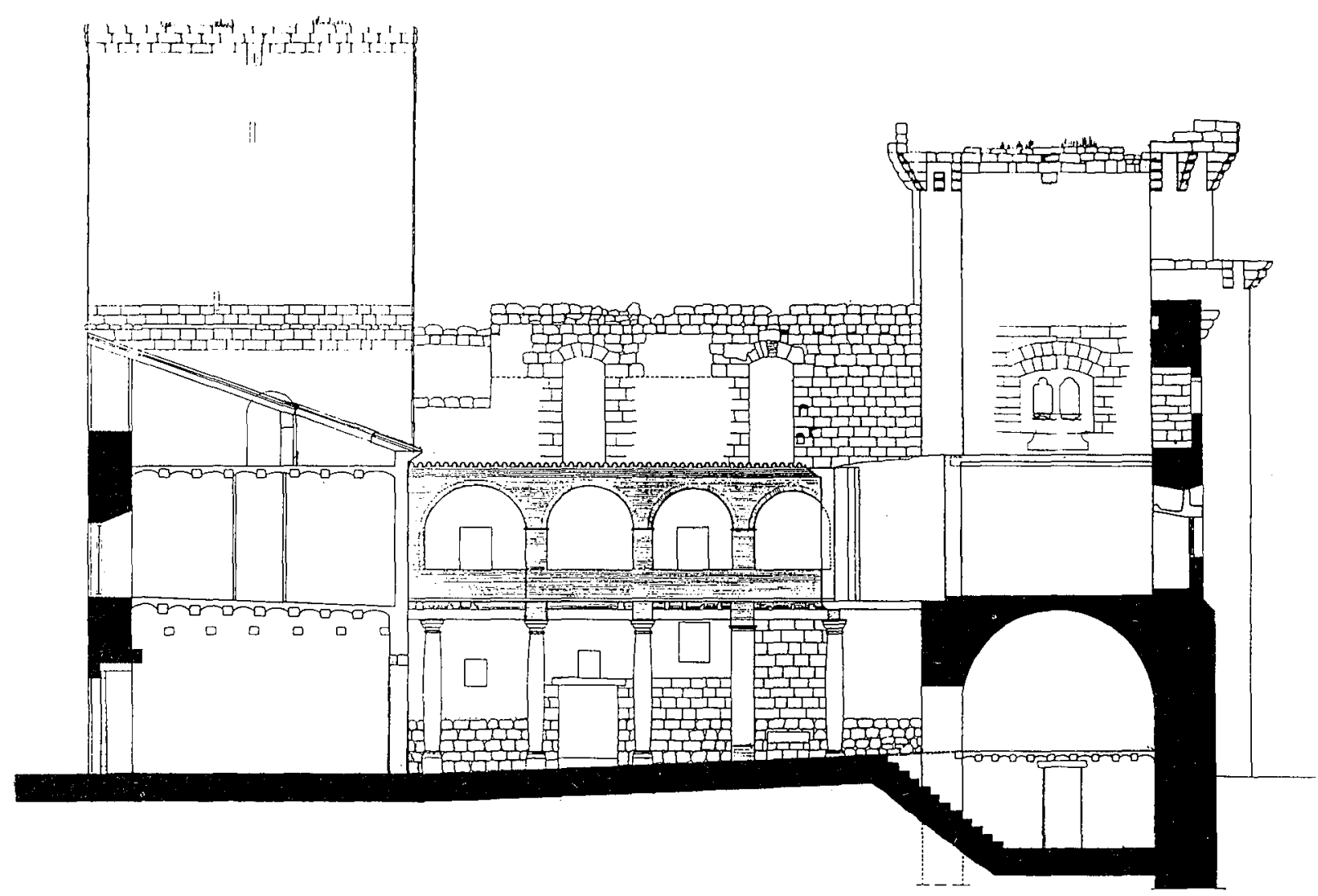

Fig. 2 Agoncillo. Sección Longitudinal. 


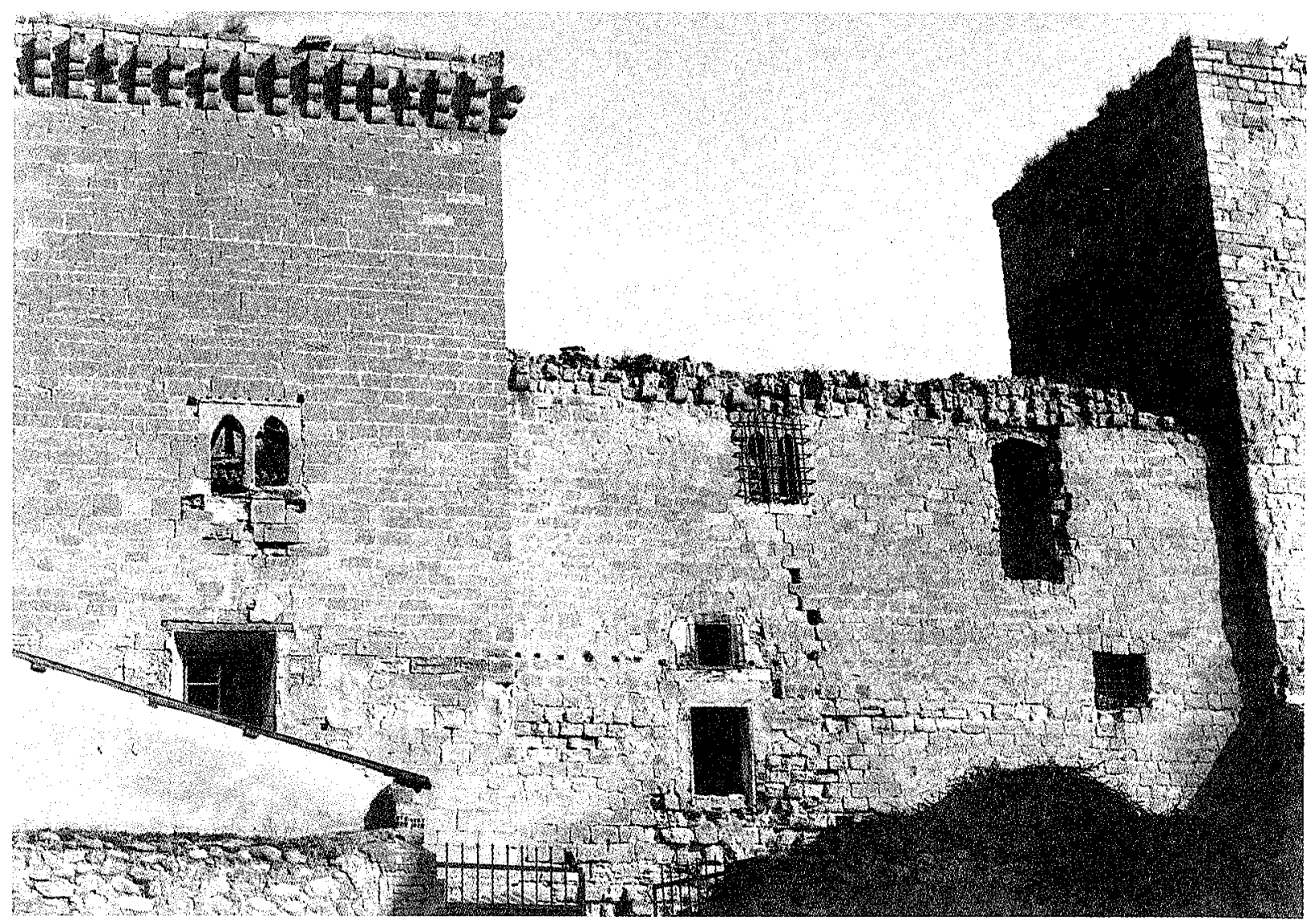

Lám. 1 Fortaleza de Agoncillo. Lado S-W.

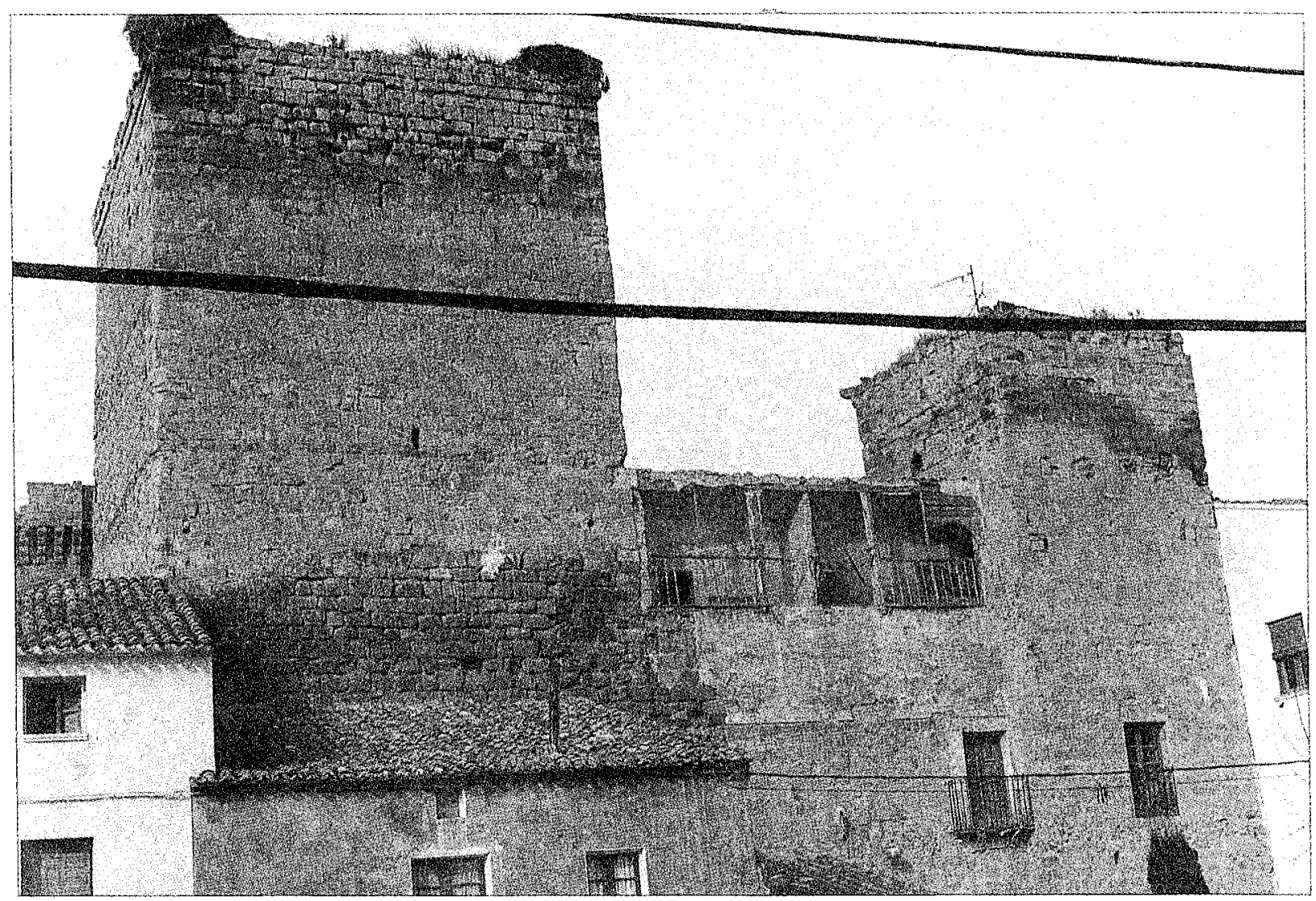

Lám. 2 Fortaleza de Agoncillo. Lado S-E. 
INOCENCIO CADIÑANOS BARDECI

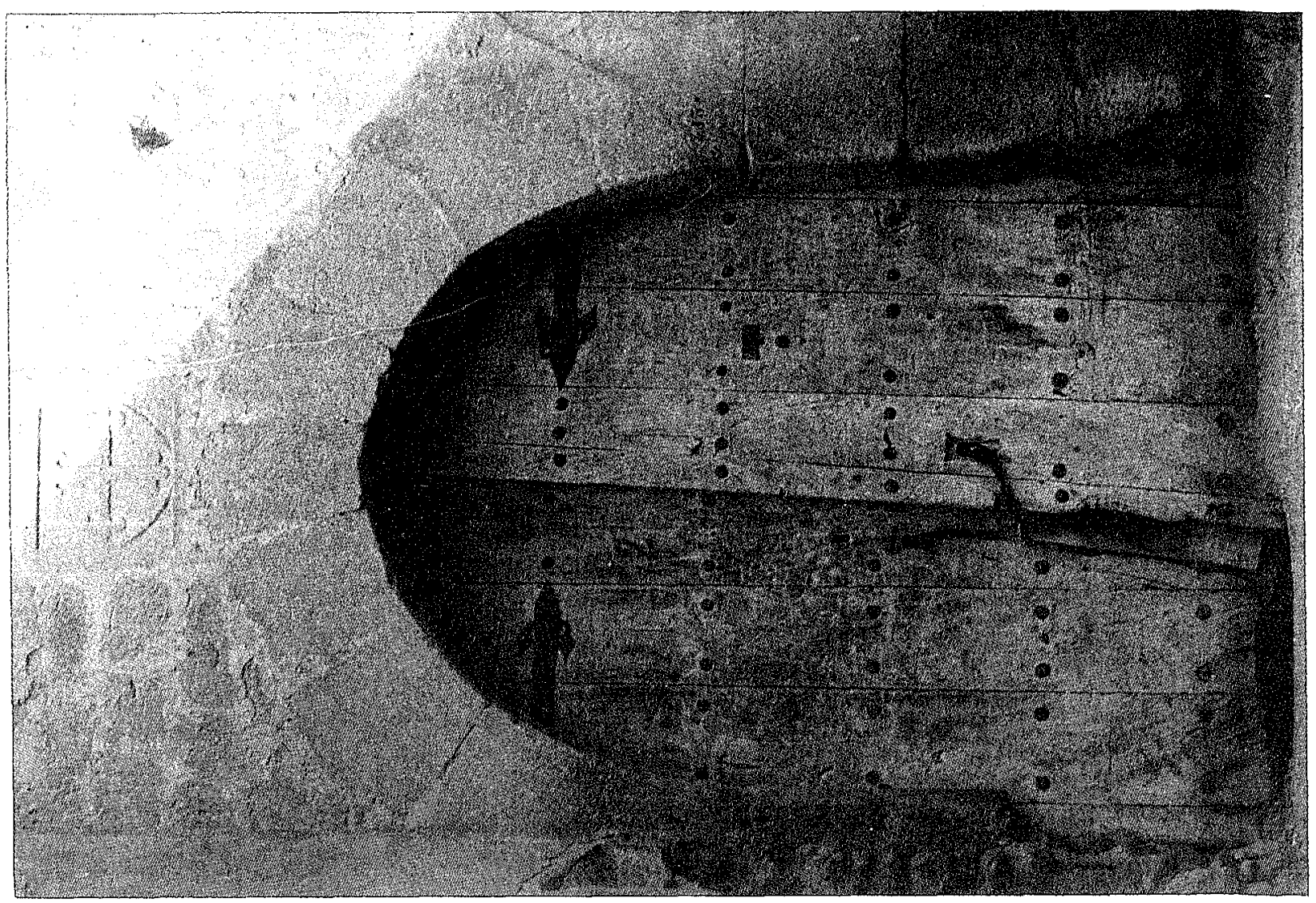

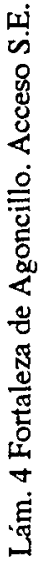

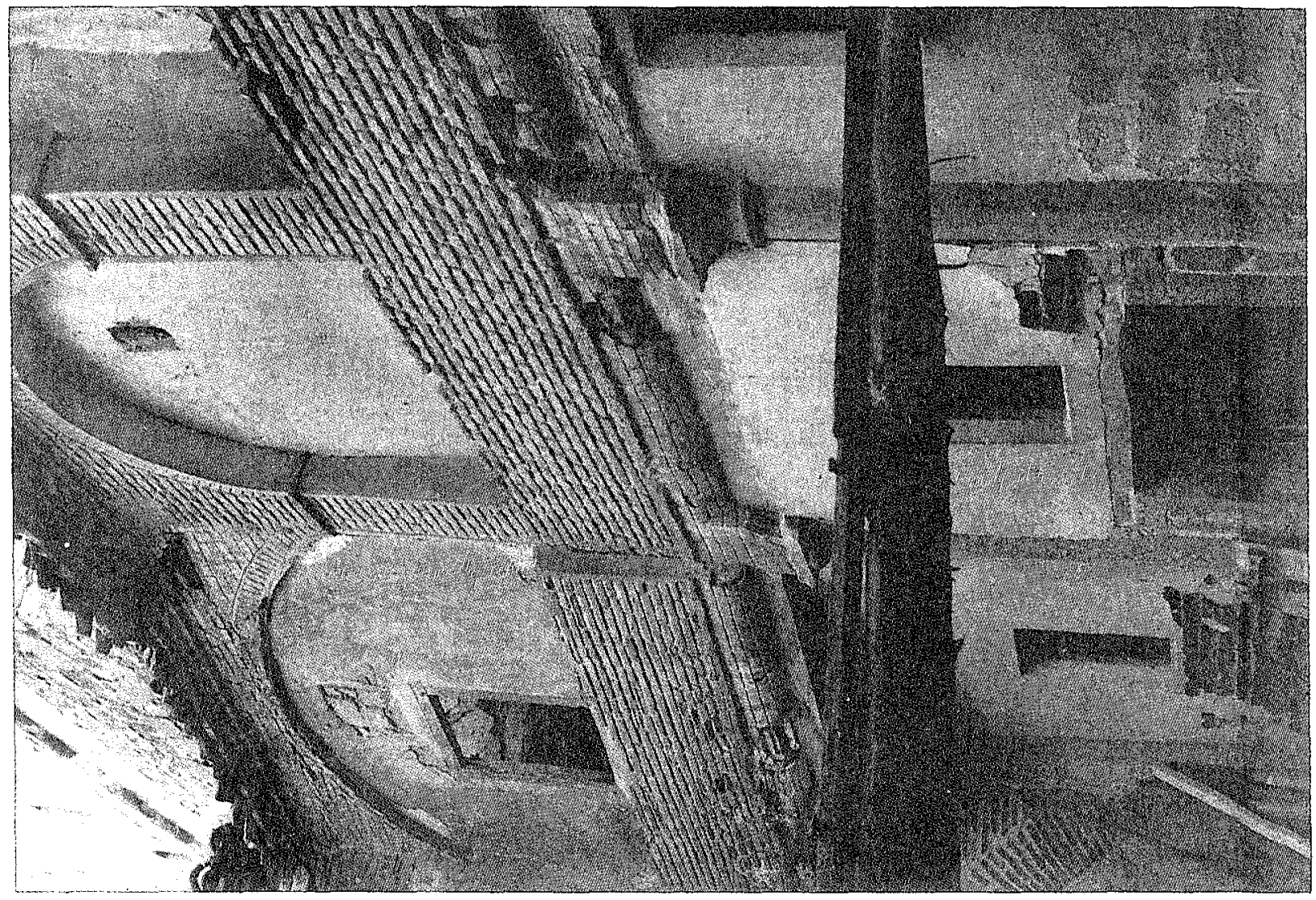

व. 